\title{
SpyGlass pancreatoscopy-guided cannulation and retrieval of a deeply migrated pancreatic duct stent
}

Proximal (upstream) migration of pancreatic duct stents is a recognized complication that occurs in up to $5.2 \%$ of patients [1], and stent retrieval is important to prevent long-term serious ductal damage. Reported techniques to remove proximally migrated pancreatic duct stents include balloon extraction, direct snare or forceps grasp, and wire cannulation with snare capture. We report a novel technique using the SpyGlass Direct Visualization System (Boston Scientific, Natick, Massachusetts, USA).

A 50-year-old woman with chronic pancreatitis underwent pancreatic endotherapy for pancreatic ductal stones. Pancreatic major papilla sphincterotomy and balloon sweeps of the pancreatic duct were carried out. At the end of the procedure, a 7-Fr plastic Teflon-coated, 7-cm long, straight pancreatic duct stent was inserted for free drainage of pancreatic juice. After 3 months, the stent was noted to have migrated proximally, reaching the tail of the pancreas ( $\bullet$ Fig. 1).

Attempts to retrieve the stent using balloon, snares, and forceps were unsuccessful. Guide wire cannulation of the stent under fluoroscopy alone was also unsuccessful. Using SpyGlass pancreatoscopy, we were able to visualize the distal end of the stent ( $\bullet$ Fig. 2).

The Spyscope's (Boston Scientific, Natick, Massachusetts, USA) four-way deflected steering capability provided improved maneuverability to successfully cannulate the stent with a 0.032 -inch Terumo guide wire ( Fig. 3), inserted via the Spyscope's accessory channel.

The Spyscope was then removed and a 7-Fr Soehendra Stent Retriever (Wilson-Cook, Winston-Salem, North Carolina, USA) was used in an over-the-wire fashion to remove the stent completely ( $\bullet$ Fig. 4).

There has only been one previous report on the use of SpyGlass pancreatoscopy to remove migrated pancreatic duct stents [2]. In that report, a 5-Fr stent was removed successfully using SpyBite (Boston Scientific, Natick, Massachusetts, USA) forceps. In our case, stent retrieval with Spy-

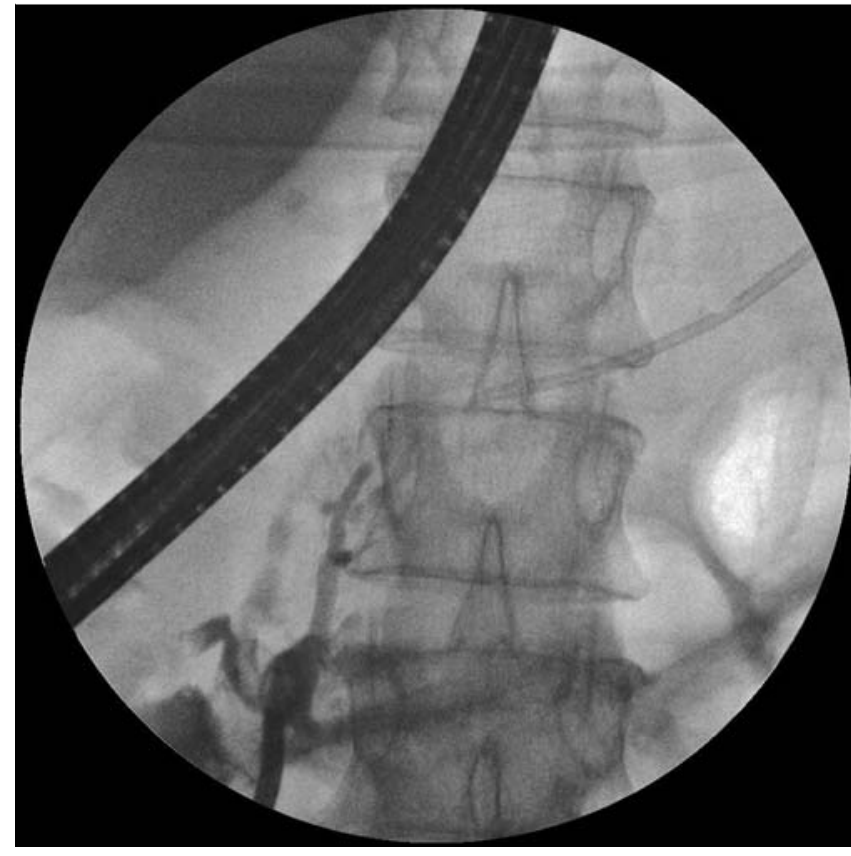

Fig. 1 Deeply migrated pancreatic duct stent.

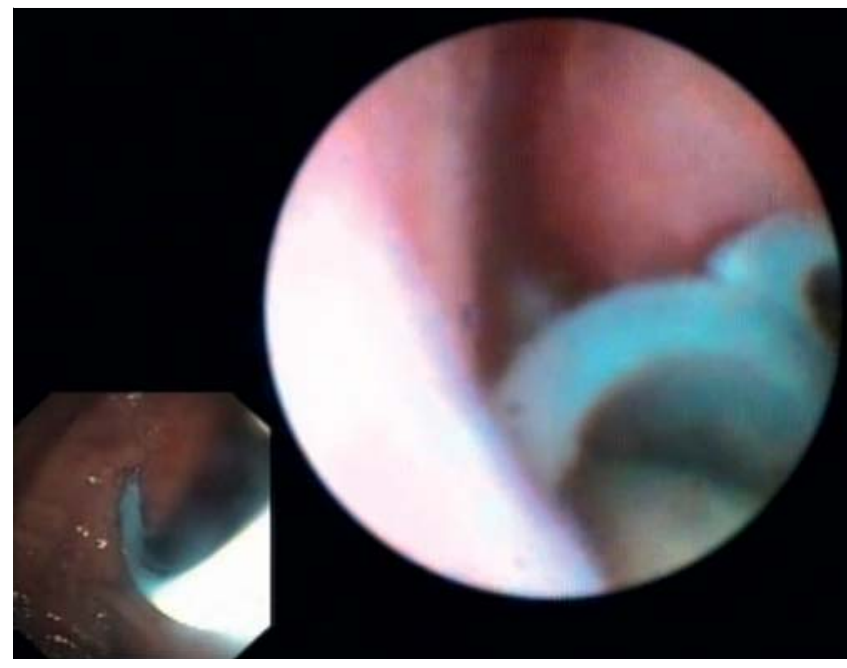

Fig. 2 Distal end of the stent visualized with SpyGlass pancreatoscopy.
Bite forceps failed as it was unable to provide a secure grasp of the larger 7-Fr stent. SpyGlass pancreatoscopy facilitates successful guide wire cannulation of migrated stents, which can then be removed with a Soehendra Stent Retriever.

Endoscopy_UCTN_Code_TTT_1AR_2AZ

Competing interests: None 


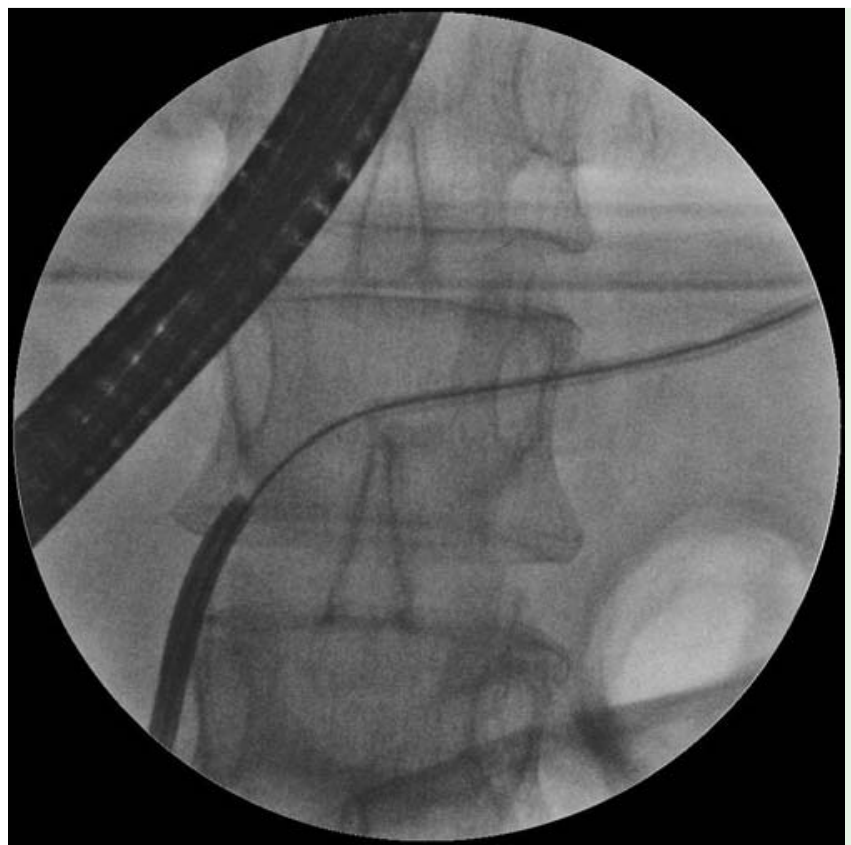

Fig. 3 Stent can-

nulated with 0.032 -inch guide wire.

\section{A. Maydeo, A. Kwek, S. Bhandari,} M. Bapat, P. Mathew

Department of Therapeutic Endoscopy, Institute of Advanced Endoscopy, Mumbai, India

\section{References}

1 Johanson JF, Schmalz MJ, Geenen JE. Incidence and risk factors for biliary and pancreatic stent migration. Gastrointest Endosc 1992; 38: 341 - 346

2 Kantsevoy SV, Frolova EA, Thuluvath PJ. Successful removal of the proximally migrated pancreatic winged stent by using the SpyGlass visualization system. Gastrointest Endosc 2010; 72: 454-455

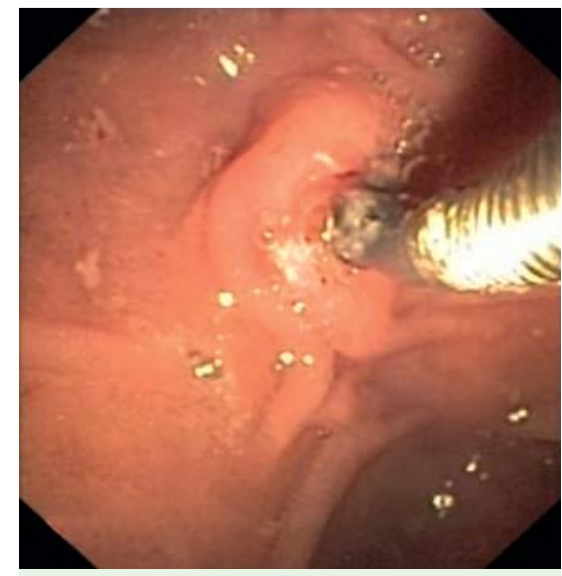

Fig. 4 Stent removed with a Soehendra Stent Retriever.

\section{Bibliography}

DOI $10.1055 / \mathrm{s}-0030-1256205$

Endoscopy 2011; 43: E137-E138

(c) Georg Thieme Verlag KG Stuttgart · New York . ISSN 0013-726X

\section{Corresponding author}

\section{A. Maydeo}

Institute of Advanced Endoscopy

5th Floor Om Chambers

Kemp's Corner

123 August Kranti Marg

Mumbai 400-036

India

Fax: +9122 23616755

ddc_endo@hotmail.com 